\title{
Research on Mechanical Performance \& Behaviour of Geopolymer Concrete Subjected to Elevated Temperatures
}

\author{
K Venkatakrishna, H Sudarsana Rao
}

\begin{abstract}
The investigative studies on mechanical performance \& behaviour, of Geopolymer Concrete (GPC) before and after the exposure to elevated temperatures $\left(\right.$ of $200^{\circ} \mathrm{C}-1000^{\circ}$ $C$ with an increment of $100^{\circ} \mathrm{C}$ ). Indicate that the GPC Specimens Exhibited better Compressive strength at higher temperatures than that of those made by regular OPC Concrete with M30 Grade. The chronological changes in the geopolymeric structure upon exposure to these temperatures and their reflections on the thermal behaviour have also been explored. The SEM images indicate GPC produced by fly ash, metakaolin and silica fume, under alkaline conditions form Mineral binders that are not only non-flammable and but are also non-combustible resins and binders. Further the Observations drawn disclose that the mass and compressive strength of concrete gets reduced with increase in temperatures.
\end{abstract}

Keywords-Geopolymer Concrete, Elevated temperature, Mechanical Performance

\section{INTRODUCTION}

Ordinary Portland Cement (OPC) is the main ingredient of concrete, the most abundantly used material on earth next to air. The rate of Concrete production/Consumption is exponentially increasing owing to steep increase in Construction activities across the world. This huge demand of concrete has its reliance on Cement industry, so on its production as well. It's estimated that worldwide cement production is annually increasing at $3 \%$.

The production of OPC releases huge amount of carbon dioxide $\left(\mathrm{CO}_{2}\right)$ to the air environment and significantly contributes to greenhouse gas emissions. It's estimated that every One ton of OPC production releases equal quantity of $\mathrm{CO}_{2}$ into the atmosphere. Also studies report that for the production of 1 ton of OPC industry requires approximately 1.5 tons of limestone, and significant amount of both fossil fuel and electrical energy. These factors necessitate researchers to find out other alternative binders to produce more environmentally friendly concrete.

The construction industry, continually demands modern building materials with lifelong performance properties under different and/or special user conditions, Concrete is generally engineered to withstand adverse environmental conditions and exposure to Fire is one such severe condition. Concrete is normally regarded as a fire resistant construction material, when compared to its other alternatives, such as steel and timber. However, when concrete structural components are exposed to fire, they are vulnerable to experience spalling. Spalling of concrete is popping out of

Revised Manuscript Received on August 19, 2019.

K Venkatakrishna, Research Scholar, JNTUA, Ananthapuramu, Andhra Pradesh, India (E-Mail: venkatakrishnajntu@gmail.com)

H Sudarsana Rao, Director IIIT-RK Valley, Idupulapaya, Andhra Pradesh, India (E-Mail: hanchate123@yahoo.co.in) small pieces of concrete from the exposed surface. This disintegration generally occurs in the initial stages of the fire, i.e., within 15 to 30 minutes. Spalling is resultant of compressive stresses parallel to the heated surface, leading to weak fractures in concrete. Spalling results in loss of the exterior layers of reinforced concrete structural component and ultimately exposes the steel reinforcement, which swiftly reduces its potency of steel when exposed to fire. This thermal incompatibility between the binder and its aggregates in concrete, results in loss of strength at elevated temperatures. The rate of expansion of the aggregates and behaviour of Binder with increments in temperatures is a significant factor and decides the performance of concrete at high temperatures.

In order to overcome this problem several researches have been carried out to introduce a binder which is not only thermoresistant, but also exhibits better characters than OPC in terms of Stability, Economy and being Eco-friendly. One such material is Geopolymer Concrete.

In preceding couple of decades noteworthy accomplishments were made through geo-synthesis and geo-polymerization and these synthesized materials have proved to be an excellent substitute to Portland cement concrete owing to the elastic properties exhibited by hardened Geopolymer concrete also the strength and performance of reinforced geopolymer concrete structural components are either similar or sometimes more superior than those observed as in the case of ordinary Portland cement concrete (Rangan, 2008). Geopolymers are inorganic resins of low viscosity that demonstrate elevated strength and fire resistance and reveal ceramic like behaviour in their properties (Davidovits, 1991). Few studies on Geopolymers reveal that some Geopolymers manufactured under high temperatures performed, exceptionally better than several ceramic materials, at elevated temperatures (Davidovits and Davidovics, 1991).

Geopolymer can be produced by activation of fly ash. Geopolymer concrete is produced by combining these resins with coarse and fine aggregates using the conventional concrete technology methods. Since fly ash is an industrial by-product from coal power stations the cost of manufacturing this concrete will be potentially lower than the conventional Portland cement based concrete.

Geopolymer is cement less concrete binder. Geopolymer concrete is acknowledged for exhibiting its high resistance to fire due to its ceramic like properties. these properties are due to the configuration of numerous crystalline alumina-silicate phases with potentially elevated melting

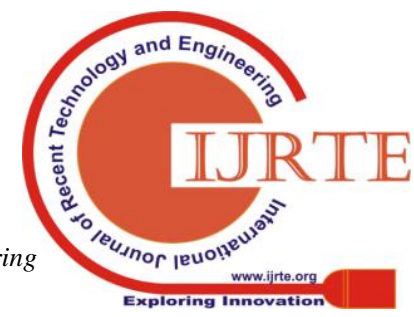


point of around $1100^{\circ} \mathrm{C}$. These physio-chemical features are believed as major reasons to conserve the structural integrity on exposure to high temperatures.

The chemical composition of the raw materials, aggregates, admixtures and alkali used determine the performance of geopolymers and its longevity. The strength of Geopolymer concrete specimens further gets enhanced after being exposed to elevated temperature due to supplementary geopolymerisation (Pan et al., 2009).

Advances in studies on chemistry of geopolymerisation have been extensively reported in many research articles. Several investigations have been timely carried out to gain knowledge of the material properties of geopolymer concrete and the structural behaviour of several geopolymer concrete structural elements like beams and columns. Also excellent number of researches are conducted on high performance geopolymer concrete and steel fibre reinforced geopolymer concretes. But only a few researchers have reported the performance of geopolymer concrete subjected to fire, in an attempt to unearth these properties the present investigation is aimed at understand the performance \& behaviour, of Geopolymer Concrete (GPC) before and after its exposure to elevated temperatures. The temperatures selected for our study ranged from $200{ }^{0} \mathrm{C}-1000{ }^{\circ} \mathrm{C}$ with an increment of $100{ }^{0} \mathrm{C}$.

Preliminary studies were carried out for the selection of a ideal mix proportion. The variables considered in the present study were fly ash to alkali ratio, percentage of aggregate, fine aggregates to total aggregate ratio, molarity of alkali, ratio of sodium silicate to sodium hydroxide, curing period and temperature to be maintained for curing and Influence of diverse admixtures like metakaoline and silica fume on engineering properties of geopolymer concrete were investigated.

The author presents information of such investigations and throws light on the effect of elevated temperatures on the compressive strength of Concretes made by adding up different admixtures.

The Compressive strength is property that governs the performance of geopolymer concrete. The strength of Geopolymer depends upon the shape, size, distribution, calcium content and the micro-structure of raw materials. The aluminium and silicon and gears of Fly Ash gets activated in presence of alkali solution which later polymerizes and results into molecular chains and behaves as a binder which bind the aggregates into a harmonized mass and there by attain best possible strength. The Calcium content of Fly Ash substantially contributes towards the strength development in Geopolymer concrete. However, low-calcium Fly ash is also opted for its better binding properties which owes to its high alumina silicate content. Alkali concentrations alkali also govern the strength of Geopolymer concrete; the concentration of alkali is proportional to its strength. amalgamation of Fly Ash, metakaolin and Silica Fume in geopolymer concrete supplement the compressive strength up to a considerable limit.

\section{MATERIALS}

\section{Fly ash}

Fly ash used in present research work is low-calcium (ASTM Class F) was collected from Raichur Thermal Power Station (RTPS) is a coal-fired electric power station located in the Raichur district of the state of Karnataka, India has been used. The chemical composition of fly ash as determined by XRF (mass percentage) is presented in Table 1. The values in the below table are confirmed to ASTM C 618 class F and IS 3812-1981. As depicted in Table1, the fly ash contained low calcium proportion. Such Low-calcium fly ash were effectively used earlier in producing geopolymer concretes (C. Antony Jeyasehar, 2013). Because of their pozzolanic activity, their compressive strength increased in later stages of curing.

Table 1: Chemical composition of fly ash

\begin{tabular}{|c|c|c|c|}
\hline Compound & $\begin{array}{c}\text { ASTM C618 } \\
\text { Class F } \\
\text { Specification } \\
\text { in \% }\end{array}$ & $\begin{array}{c}\text { IS 3812 } \\
\text { specificati } \\
\text { on } \\
\text { in \% }\end{array}$ & $\begin{array}{c}\text { Percenta } \\
\text { ge (mass) }\end{array}$ \\
\hline $\begin{array}{c}\mathrm{SiO}_{2}+ \\
\mathrm{Al}_{2} \mathrm{O}_{3}+ \\
\mathrm{Fe}_{2} \mathrm{O}_{3}\end{array}$ & $>70$ & $>70$ & 86.31 \\
\hline $\mathrm{CaO}$ & $<5$ & - & 1.81 \\
\hline $\mathrm{SO}_{3}$ & $<5$ & $<2.75$ & 0.55 \\
\hline $\mathrm{Na}_{2} \mathrm{O}$ & $<1.5$ & $<1.5$ & 0.4 \\
\hline $\mathrm{MgO}$ & - & $<5$ & 1.1 \\
\hline$* \mathrm{LOI}$ & $<6$ & $<12$ & 1.36 \\
\hline
\end{tabular}

*Loss on Ignition

\section{Aggregates}

To prepare a sound concrete mix, the aggregates are be clean, hard, strong, free from engrossed chemicals or coatings of clay and all other fine materials that could probably cause the deterioration of the concrete. Coarse aggregates with nominal maximum sizes in range of 12.5 $\mathrm{mm}$ to $20 \mathrm{~mm}$ made up of granite were used. The grading of aggregates also plays a important role in influencing the properties of concrete, including drying, shrinkage and workability of concrete. Grading of aggregates was done in accordance with the IS 383 - 1970. Surface texture of aggregate plays vital role in developing the bond between an aggregate particles and a cementing material. A rough surface texture gives better grip, resulting in a stronger bond, and thus creating tough concrete. The granular textured aggregates complying with the CED2 (7919) were opted. For Fine aggregates particles passing through a $4.75 \mathrm{~mm}$ sieve were selected and used.

\section{Fine Aggregates}

River sand from Chitravathi river, Ananthapur Dist, Andhra Pradesh was used as fine aggregates and was tested as per IS: 2386 (part III). results of Sieve analysis for fine aggregates is shown in Table 2 
Table 2 sieve analysis result of fine aggregate

\begin{tabular}{|c|c|c|c|c|}
\hline $\begin{array}{c}\text { IS sieve } \\
\text { size }\end{array}$ & $\begin{array}{c}\text { Mass } \\
\text { Retained } \\
\text { on Sieve } \\
\text { (gm) }\end{array}$ & $\begin{array}{c}\text { Cumulati } \\
\text { ve Mass } \\
\text { Retained } \\
\text { (gm) }\end{array}$ & $\begin{array}{c}\text { Cumulat } \\
\text { ive \% } \\
\text { Mass } \\
\text { Retained }\end{array}$ & $\begin{array}{c}\text { Cumulat } \\
\text { ive \% } \\
\text { Passing }\end{array}$ \\
\hline $4.75 \mathrm{~mm}$ & - & - & - & - \\
\hline $2.36 \mathrm{~mm}$ & 91.6 & 91.6 & 4.58 & 95.42 \\
\hline $1.18 \mathrm{~mm}$ & 105.56 & 197.16 & 9.858 & 90.142 \\
\hline $600 \mu$ & 913.08 & 1110.24 & 55.512 & 44.488 \\
\hline $300 \mu$ & 741.58 & 1851.82 & 92.591 & 7.409 \\
\hline $150 \mu$ & 107.16 & 1958.98 & 97.949 & 2.051 \\
\hline Pan & 41.02 & 2000 & 100 & 0 \\
\hline
\end{tabular}

The fine aggregates were found to have an average fineness modulus of 2.7 (acceptable limit 2.6 to 2.9) and the absorption value of fine aggregate was $0.99 \%$ which was within the acceptable limit of $2 \%$.

\section{Alkaline Activators}

The alkaline activators were formed fly by a combination of $12 \mathrm{M}$ sodium Hydroxide $(\mathrm{NaOH})$ and sodium silicate $\left(\mathrm{Na}_{2} \mathrm{SiO}_{3}\right)$ solutions. The properties and composition of the sodium silicate solution $\left(\mathrm{Na}_{2} \mathrm{SiO}_{3}\right)$ supplied by the producer are shown in Table 3.

Table 3 Test results of Sodium silicate

\begin{tabular}{|c|c|c|}
\hline SI No & Constituents & Percentage composition \\
\hline 1 & $\mathrm{Na}_{2} \mathrm{O}$ & 14.1 \\
\hline 2 & $\mathrm{SiO}_{2}$ & 28.9 \\
\hline 3 & Water & 55.8 \\
\hline
\end{tabular}

\section{Superplasticizer}

To accomplish superior workability in the concrete, Naphthalene based Super plasticizer was used at rate of $2 \%$ of the binder's weight. It's learnt to possess specific gravity of 1.2 with a solids content of about $40 \%$.

\section{Silica fume}

The main objective of the present investigation was to study the effect of addition of silica fume on the performance of Geopolymer concrete and investigate it's effect on the mechanical properties. Silica fume known as micro-silica, obtained from furnaces used in the production of silicon and ferrosilicon alloys, it was in fine powder form with $90 \% \mathrm{SiO}_{2}$, Composition of silica fume is as shown in below Table 4 .

Table 4 Composition of silica fume

\begin{tabular}{|c|c|c|c|c|c|c|c|c|c|}
\hline $\begin{array}{c}\text { Chemi } \\
\text { cal } \\
\text { compo } \\
\text { sition }\end{array}$ & $\begin{array}{c}\mathbf{S i} \\
\mathbf{O}_{2}\end{array}$ & $\begin{array}{c}\mathbf{A l}_{\mathbf{2}} \\
\mathbf{O}_{\mathbf{3}}\end{array}$ & $\begin{array}{c}\mathbf{F e}_{\mathbf{2}} \\
\mathbf{O}_{\mathbf{3}}\end{array}$ & $\begin{array}{c}\mathbf{C} \\
\mathbf{a} \\
\mathbf{O}\end{array}$ & $\begin{array}{c}\mathbf{M} \\
\mathbf{g O}\end{array}$ & $\begin{array}{c}\mathbf{K}_{\mathbf{2}} \\
\mathbf{O}\end{array}$ & $\begin{array}{c}\mathbf{N a} \\
{ }_{2} \mathbf{O}\end{array}$ & $\begin{array}{c}\mathbf{S} \\
\mathbf{O} \\
\mathbf{3}\end{array}$ & $\begin{array}{c}\mathbf{L} \\
\mathbf{O} \\
\mathbf{I}\end{array}$ \\
\hline $\begin{array}{c}\text { Silica } \\
\text { fume( } \\
\%)\end{array}$ & $\begin{array}{c}90 . \\
00\end{array}$ & $\begin{array}{c}0.4 \\
3\end{array}$ & 1.5 & $\begin{array}{c}0.2 \\
3\end{array}$ & $\begin{array}{c}0.2 \\
9\end{array}$ & $\begin{array}{c}0.4 \\
6\end{array}$ & $\begin{array}{c}0 . \\
2\end{array}$ & 1. \\
\hline
\end{tabular}

\section{Metakaoline}

Highly reactive metakaoline was purchased from a reputed Industrial chemical Distrubutor from bangalore. The chemical composition results of the metakaolin is listed in Table 5.

Table 5 Composition of silica fume

\begin{tabular}{|c|c|c|c|c|c|c|c|c|}
\hline $\begin{array}{c}\text { Chemic } \\
\text { al } \\
\text { composi } \\
\text { tion }\end{array}$ & $\begin{array}{c}\mathbf{S i} \\
\mathbf{O}_{\mathbf{2}}\end{array}$ & $\begin{array}{c}\mathbf{A l}_{\mathbf{2}} \\
\mathbf{O}_{\mathbf{3}}\end{array}$ & $\begin{array}{c}\mathbf{F e}_{2} \\
\mathbf{O}_{\mathbf{3}}\end{array}$ & $\begin{array}{c}\mathbf{C a} \\
\mathbf{O}\end{array}$ & $\begin{array}{c}\mathbf{P}_{\mathbf{2}} \\
\mathbf{O}_{\mathbf{5}}\end{array}$ & $\begin{array}{c}\mathbf{K}_{\mathbf{2}} \\
\mathbf{O}\end{array}$ & $\begin{array}{c}\mathbf{N a}_{2} \\
\mathbf{O}\end{array}$ & $\begin{array}{c}\mathbf{S O} \\
\mathbf{3}\end{array}$ \\
\hline $\begin{array}{c}\text { Metakao } \\
\text { line (\%) }\end{array}$ & 54. & 44. & 0.5 & 0.1 & 0.4 & 0.1 & 0.2 & 0.0 \\
& 6 & 6 & 5 & 4 & 6 & 2 & 21 \\
\hline
\end{tabular}

The sodium silicate solution and sodium hydroxide solution where mixed together one day before adding the liquid to the solid constituents. The fly ash with replacements such as silica fume / metakaoline and the aggregates are first mixed together in a mixing pan for about 5 minutes manually once the dry mix is done, the prepared alkaline solution is thoroughly mixed with the dry mix for another 5 minutes to make fresh Geopolymer concrete

The fresh concrete was placed in the moulds were specimens were compacted in three layers followed by an additional vibration of 10 seconds using a vibratory table. Different batches were implemented for Silica fume and Metakaoline. The so prepared Geopolymer concrete cube specimens of size $150 \times 150 \times 150 \mathrm{~mm}$ size were used for compressive strength determination. these samples were kept in muffle furnace for $3 \mathrm{hr}$ duration at varying elevated temperature so as to simulate fire breakout like conditions and later cooled to room temperature ( as if no fire fighting equipments are approaching the site and structure is exposed to ambient air and hence air cooled ) and so cubes were brought to room temperature and were tested in compressive testing machine to evaluate compressive strength of Geopolymer concrete.

\section{RESULTS AND DISCUSSIONS}

The mean values of the compressive strengths obtained from the experimental results are as presented in form of tables and bar-charts and are discussed in detail. The effects of elevated temperature with loss of weight in Geopolymer concrete composites are also discussed.

It was be noted that for the lower temperatures in range of $100^{\circ} \mathrm{C}$ and $350^{\circ} \mathrm{C}$, GPC lost approximately $20-25 \%$ of its strength after the initial Three hours of heating. This early loss of strength, in particular at $100^{\circ} \mathrm{C}$, can be attributed to the loss of free water from the Geopolymeric system. This evaporation of water particles results in free pores and voids which results in compromise in integrity of the whole matrix. Moreover, this temperature was not adequate, for chemical modifications to crop up within the matrix, which resulted in strength gain, as was in the case for the high temperature tests. However, at higher temperatures a significant increase is strength was noticed. This indicated that the persistent heat catalysed the reaction between the unreacted particles of fly ash and alkaline solution resulting is a reasonable strength development. At $350^{\circ} \mathrm{C}$ the rate of strength loss was considerably sluggish as compared to $100^{\circ} \mathrm{C}$ heating. At higher temperatures of $600^{\circ} \mathrm{C}$, $800^{\circ} \mathrm{C}$ and $1000^{\circ} \mathrm{C}$ the strength loss was estimated to exist in rage of $30-40 \%$. One probable 
grounds of this decrease in strength may be the incompatibilities between the different phases of concrete.

The results show high shrinkage in compressive strength with increase in fire (temperature) in the range $800^{\circ} \mathrm{C}-1000^{\circ}$ C. The compressive strength of flash based Geopolymer concrete with $10 \%$ replacement of metakaoline and $15 \%$ replacement of silica fume with flyash are tested and are given in table 6 and table 7 respectively.

Table 6: Variation in compressive strength of Metakaoline based GPC with elevated temperature upto $1000^{0} \mathrm{C}$

\begin{tabular}{|c|c|c|}
\hline \multicolumn{3}{|c|}{ Compressive strength in Mpa } \\
\hline Temperature ${ }^{\mathbf{0}} \mathbf{C}$ & $\begin{array}{c}\text { Conventional } \\
\text { concrete }\end{array}$ & Metakaoline \\
\hline 100 & 38.10 & 39.07 \\
\hline 200 & 37.34 & 37.90 \\
\hline 300 & 36.59 & 36.76 \\
\hline 400 & 35.86 & 35.66 \\
\hline 500 & 35.14 & 34.59 \\
\hline 600 & 34.44 & 33.55 \\
\hline 700 & 33.75 & 32.55 \\
\hline 800 & 33.08 & 31.57 \\
\hline 900 & 32.41 & 30.62 \\
\hline 1000 & 31.77 & 29.70 \\
\hline
\end{tabular}

Table 7: Variation in compressive strength of Silica fume based GPC with elevated temperature upto $1000^{\circ} \mathrm{C}$

\begin{tabular}{|c|c|c|}
\hline \multicolumn{3}{|c|}{ Compressive strength in Mpa } \\
\hline Temperature ${ }^{\mathbf{0}} \mathbf{C}$ & $\begin{array}{c}\text { Conventional } \\
\text { concrete }\end{array}$ & Silica fume \\
\hline 100 & 38.10 & 40.18 \\
\hline 200 & 37.34 & 38.98 \\
\hline 300 & 36.59 & 37.42 \\
\hline 400 & 35.86 & 36.29 \\
\hline 500 & 35.14 & 34.84 \\
\hline 600 & 34.44 & 33.80 \\
\hline 700 & 33.75 & 30.42 \\
\hline 800 & 33.08 & 29.51 \\
\hline 900 & 32.41 & 28.62 \\
\hline 1000 & 31.77 & 27.76 \\
\hline
\end{tabular}

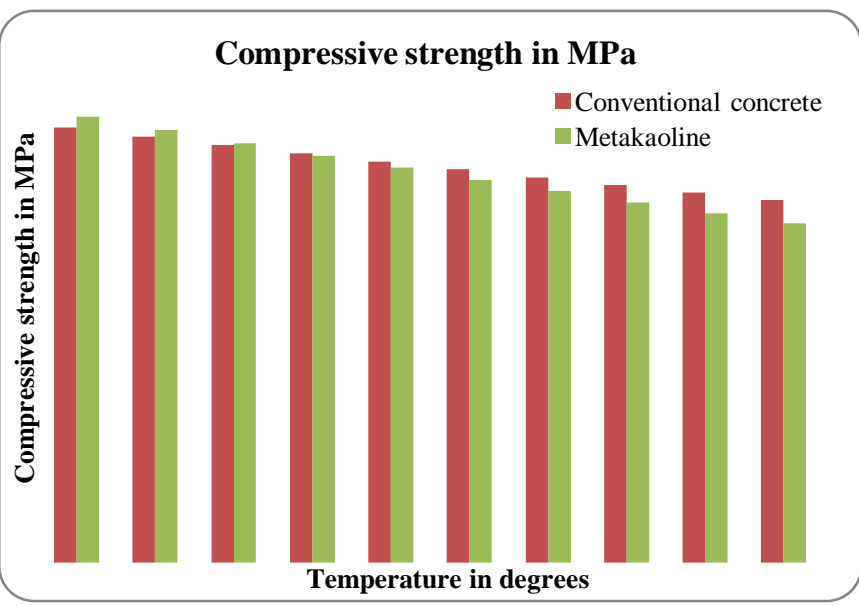

Figure 1: Variation in compressive strength of Metakaoline based GPC with elevated temperature upto

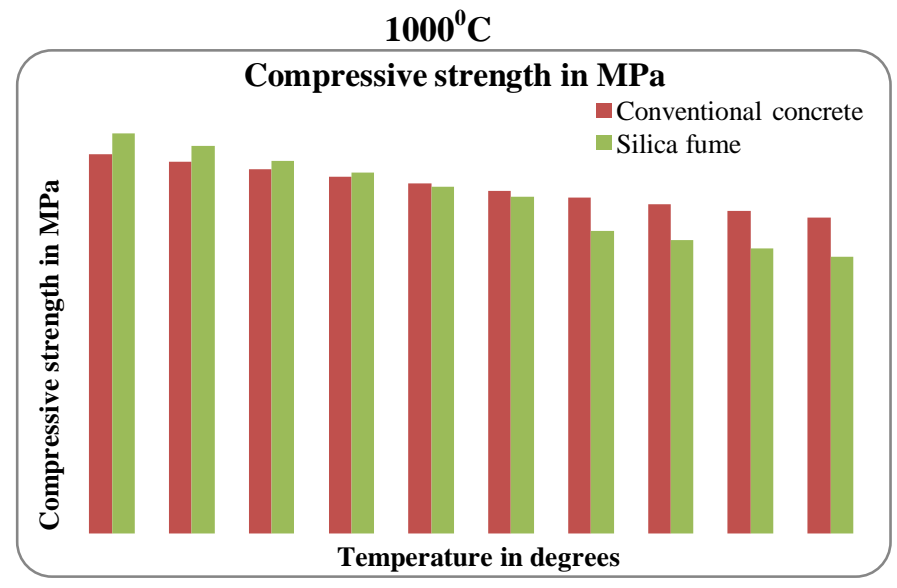

Figure 2 : Variations in compressive strength of Silica fume based GPC with elevated temperature upto $1000^{\circ} \mathrm{C}$

\section{CONCLUSIONS}

Based on the present study, the following conclusions may be drawn

1. There is a definite proportion for various ingredients to achieve maximum strength properties.

2. The ratio of sodium silicate solution to-sodium hydroxide solution was fixed as 2.5 . The ratio of fly ash: sand: coarse aggregate was 1:1.015:2.368 with ratio of activator solution to fly ash as 0.45 .

3. Ultimate strength development in Geopolymer concrete was achieved by the proper selection of curing temperature and the period of curing. In this case 25.98 $\mathrm{MPa}, 40.18$ and 40.77 were obtained when fly ash was replaced partially by silica fume and in metakaoline case 24.53 , 39.07and 40.54 were obtained when fly ash replaced partially with metakaoline used at $100^{\circ} \mathrm{C}$ and gradually decreased with increase in temperature.

4. Fly ash based Geopolymer concrete undergoes a high rate of strength loss (compressive strength, tensile strength and modulus of elasticity) during its early heating period (up to $1000{ }^{\circ} \mathrm{C}$ ) compared to OPC concrete.

5. When Geopolymer concrete was exposed to temperatures beyond $1000{ }^{\circ} \mathrm{C}$, the unreacted crystalline materials in Geopolymer concrete get transformed into amorphous state and undergo polymerization. As a result, there is no further strength loss (compressive strength) in Geopolymer concrete.

\section{REFERENCES}

1. K.Zulkifly, H.C. Yong, MMAB Abdullah, LY Ming, D Panias and K.Sakkas(2017), Review of Geopolymers Behaviour in thermal Environment, IOP Conference Series: Materials Science \& Engineering, 209, 1-8.

2. Daniel L.Y.Kong, Jay G. Sanjayan(2014), Effect of elevated temperatures on Geopolymer paste, mortar \& concrete, Elsevier Cement \& Concrete Research, http://ees.elsevier.com, Issue 40, 334-339.

3. FUA Shaikh, V.Vimonsatit (2014), Compressive Strength of Fly-ash-based Geopolymer concrete at elevated temperatures, Fire and materials wiley Online Library, DOI:10.1002/fam. 
4. Chandan kumar, Krishna Murari, C.R.Sharma (2014),Performance \& Geopolymer concrete at elevated Temperature and against Aggressive Chemical Environment, International Journal of Innovative Research in Science, Engineering \& technology, Volume 3, Issure 6, 13366-13373.

5. Omar A Abdulkareem, AM Mustafa AI Bakri, H. Kamarudin I Khairul Nizar \& Alaeddin A Saif (2014), Effects of Elevated Temperatures on the thermal behaviour and mechanical performance of fly ash Geopolymer paste, mortar and lightweight concrete, Elsevier, Construction and Building Materials, www.elsevier.com, Issue 50, 377-387.

6. Shweta Mane \& H.S. Jadhav (2012), Investigation of Geopolymer Mortars and Concrete Under High Temperature, International Journal of Emerging Technology and Advanced Engineering, www.ijetae.com, Volume 2, Issue 12, 384-390.

7. EmreSancakY.Dursun Sari OsmanSimsek (2008),Effects of elevated temperature on compressive strength and weight loss of the light-weight concrete with silica fume and superplasticizer, Elsevier Cement \& Concrete Composites, Volume 30, Issue 8, Pages 715-721.

8. Daniel L.Y.Kong, Jay G. Sanjayan, Kwesi Sagoe-Crentsil(2007), Comparative performance of Geopolymers made with metakaolin and fly ash after exposure to elevated temperatures, Elsevier Cement \& Concrete Research,www.sciencedirect.com, Issue 37, 1583-1589.

9. Peter Duxson, Grant C. Lukey, Jannie S. J. van Deventer(2007), Physical evolution of Na-geopolymer derived from metakaolin up to $1000{ }^{\circ} \mathrm{C}$, Journal of Material Science, Volume 42, Issue 9, pp 3044-3054

10. M.SaadS.A. Abo-El-Enein G.B.Hanna M.F.Kotkata (1996), Effect of temperature on physical and mechanical properties of concrete containing silica fume, Elsevier Cement \& Concrete Research, Volume 26, Issue 5, Pages 669-675.

11. Zhu Pan ,Jay G. Sanjayan ,B. V. Rangan, An investigation of the mechanisms for strength gain or loss of Geopolymer mortar after exposure to elevated temperature, Journal of Material Science, Volume 7, Issue 44, 1873-1880.

12. Davidovits J, J. THERM. ANAL. (1991), Geopolymer: inorganic polymeric new materials 91 , Volume 37 , Issue $8,1633-1656$. 